$\mathbb{T}$ periodica polytechnica

Civil Engineering

$55 / 1(2011) 73+79$

doi: 10.3311/pp.ci.2011-1.09

web: http://www.pp.bme.hu/ci

(C) Periodica Polytechnica 2011

RESEARCH ARTICLE

\section{Application of anchors under special concrete conditions}

\author{
Rita Nemes / Éva Lublói
}

Received 2010-06-21, revised 2010-10-13, accepted 2010-12-08

\begin{abstract}
Expansion and bonded anchors respond different ways in case of the special compound or the increase of temperature. Bond strength of an anchor is influenced not only by the strength of concrete, but also by its composition. The behaviour of expansion and bonded anchors is different in normal weight concrete $(N W C)$ and lightweight aggregate concrete (LWAC). Five different concrete mixtures were studied. The compressive strength of NWC and one of LWAC were the same. And the composition of LWAC was changed. In our experimental study torque controlled expansion anchors as well as bonded anchors (vinyl ester or vinyl ester with cement adhesive) were tested. In case of temperature loading the anchors were installed at room temperature in concrete blocks, than were previous heated up to $150^{\circ} \mathrm{C}$ or $300^{\circ} \mathrm{C}$. Reference tests were also carried out on specimens stored continuously at room temperature. Our experimentally study was carried out with two different concrete strengths.
\end{abstract}

\section{Keywords}

expanded anchors $\cdot$ bonded anchors $\cdot$ lightweight aggregate concrete $\cdot$ high temperatures

\section{Acknowledgement}

This work is connected to the scientific program of the Development of quality-oriented and harmonized $R+D+I$ strategy and functional model at BME project. This project is supported by the New Hungary Development Plan (Project ID: TÁMOP4.2.1/B-09/1/KMR-2010-0002).

\section{Rita Nemes}

Department of Construction Materials and Engineering Geology, BME, H-1521 Budapest, Hungary

e-mail: nemes.rita@gmail.com

\section{Éva Lublói}

Department of Construction Materials and Engineering Geology, BME, H-1521 Budapest, Hungary

e-mail: lubeva@web.de

\section{Introduction}

1.1 Behaviour of expansion and bonded anchors

Several types of anchors are available for concretes for loadtransfer.

Mechanical anchors under tension can have the following failure modes: steel failure, concrete cone failure, concrete breakout, pullout and concrete splitting (Fig. 1) [1, 2]. The type of failure mode depends on strength properties of the materials and the state of concrete (uncracked or cracked etc.). It would be prosperous if the load bearing capacity of the anchor, the concrete and the bond between anchor and concrete would be about equal, and so all the materials would be fully exploited. These anchors have two main groups: cast-in-place and post-installed anchors. Post-installed anchors were studied, these also have two types: expansion and bonded anchors. One type of expansion and two types of bonded anchors were tested.

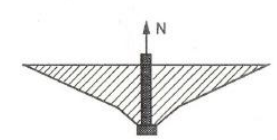

a)

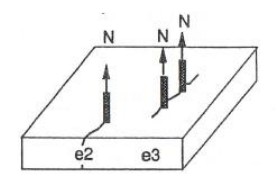

d)
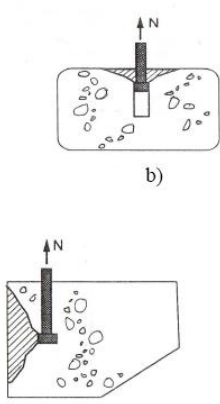

e)

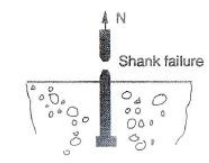

Fig. 1. Failure modes observed for expansion anchors under tensile loading [1]. a) concrete cone, b) concrete cone with pull out, c) steel failure, d) pull out, e) shell

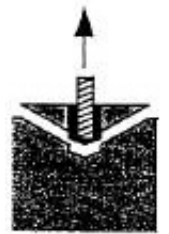

a)

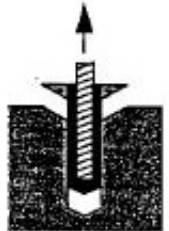

b)
Fig. 2. Failure modes observed for adhesive anchors under tensile loading [1]. a) concrete cone, b) concrete cone with bond failure 


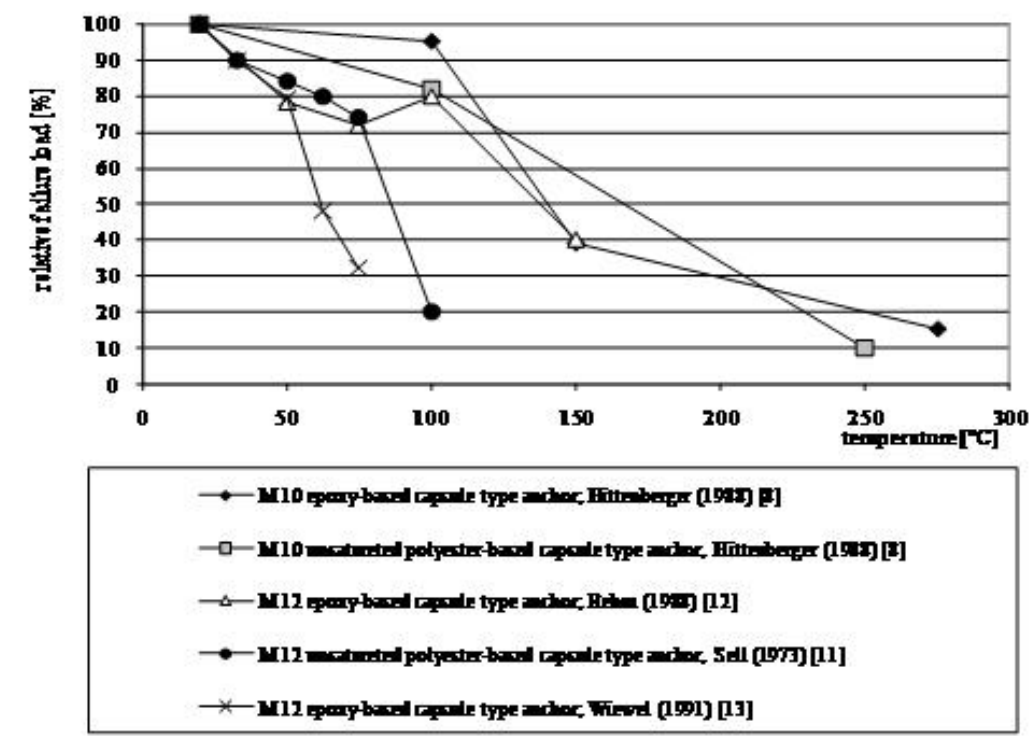

Fig. 3. Relative failure load as a function of the temperature [14]

Bonded anchors transfer tension loads to the base material by bond between anchor shank and mortar as between mortar and wall of drilled hole. For bonded anchors the failure modes are as for mechanical anchors in addition to bond failure. If the embedment depth of the bonded anchor is very small, then usually the concrete cone is pulled out. If the embedment depth of the anchor is deeper, a shallow concrete cone together with bond failure under the cone is observed (Fig. 2).

Simons, Eligehausen and Kirtzakis (2005) found that by bonded anchors the bond stress and the bond stiffness in cracked and uncracked concrete are very important. Bond stress and the bond stiffness were reduced for cracked concrete compared to uncracked concrete. The reduction of the bond strength was independent of the concrete strength [3]. Adhesive materials for bonded anchors can be made of organic compounds (epoxy, polyester or vinyl ester), inorganic compounds (cementitious) and combination of organic and inorganic compounds [4,5].

\subsection{The influence of the type of aggregate}

Concrete failure depends on the strength of concrete according to the literature. The anchors have instructions for minimum strength class of concrete. In case of lightweight aggregate concrete, apart from the strength the density of concrete is also relevant. Strength of LWAC can be changed by the changing of strength of cement mortar matrix or by changing of crushing resistance of lightweight pellets [6]. Lightweight aggregate concrete apart from the compressive strength class, density class is also given [7]. By defining further mechanical properties (for example Young's modulus) the density of concrete also should be considered [8]. Possibly the density influences the load bearing capacity and the failure mode of the anchorage. Special anchors for lightweight concrete (for masonry elements) exist, but structural lightweight aggregate concrete has a minimum strength class LC12/13 and its inside structure is the same as normal weight concrete (their cement mortar matrix is saturated or over-saturated). Anchors for normal weight concrete are applicable in lightweight aggregate concrete but the load bearing capacity may be different (lower).

\subsection{The influence of the temperature}

After temperature loading the material characteristic could be changed significantly [9]. In case of bonded anchors glass transition temperature of the adhesive is important. Bond strength is significantly reduced above the adhesive glass transition temperature. Relative failure loads as a function of the temperature [2, 10, 12] are presented in Fig. 3 for bonded anchors with epoxy based or polyester based adhesives.

Metallic post-installed and undercut anchors were experimentally studied by Bamonte, Gambarova (2005) in thermally damaged concrete. The shank diameter was $10 \mathrm{~mm}$. The effective depth was $80 \mathrm{~mm}$. The anchors were installed into the previous heated surface. The observed peak load was linearly decreasing by increase of the previous temperature load (Fig. 3] [13- -15$]$. The failure mode is also affected by the temperature. At room temperature failure of the steel shank took place.

Ožbolt, Kožar, Eligehausen and Periskič (2004) indicated by FEM analysis the largest reduction of the load bearing capacity is obtained for anchors with relatively small embedment depth. By heating of concrete the resistance is generally decreasing, however, when the concrete member is heated than cooled down, the resistance can increase and it can even be larger than the resistance of the anchor in unheated concrete [16]. 


\section{Test methods}

\subsection{The tested anchors}

Three different anchors were tested. One type was a torquecontrolled expansion anchor (FBN 8/50+63 K, Fig. 44 and two types of bonded anchors (FIS A 8x175, Fig. 55. Bonded anchors were with vinyl ester (FIS VT 380 C) and hybrid (FIS V 360 S, vinyl ester + cement) bonding agent. All tested anchors were of $8 \mathrm{~mm}$ in diameter and the embedment depth was $50 \mathrm{~mm}$.

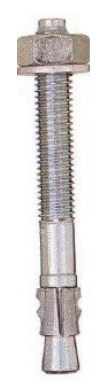

Fig. 4. Torque-controlled expansion anchor [17]

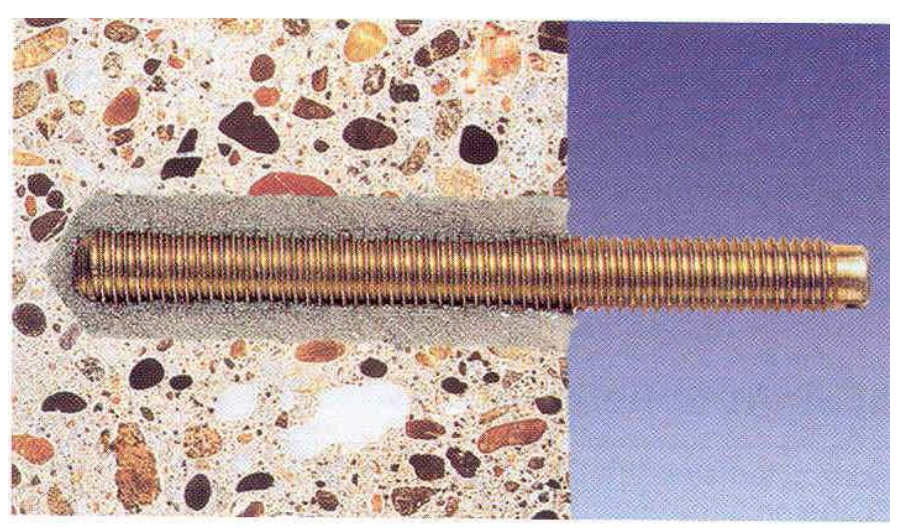

Fig. 5. Bonded anchor 17]

\subsection{Concrete mixtures}

Our experimentally study was carried out with two different normal weight concrete strengths and three different lightweight concrete mixtures.

As reference, a normal weight concrete with $\mathrm{C} 25 / 30$ (Mixture A, Tab.11 and C45/55 (Mixture B, Tab.22) strength class was tested too. The experiment with temperature loading were carried out by both normal weight concrete mixtures $\left(20^{\circ} \mathrm{C}, 150^{\circ} \mathrm{C}\right.$, $\left.300^{\circ} \mathrm{C}\right)$.

Tab. 1. Composition of Mixture A

\begin{tabular}{ccc}
\hline Mixture A & C25/30 & $\mathrm{kg} / \mathrm{m}^{3}$ \\
\hline cement & CEM I 42.5 N & 300 \\
\hline water & & 165 \\
\hline aggregate 1 & natural quartz sand 0/4 & 903 \\
\hline aggregate 2 & natural quartz gravel 4/8 & 408 \\
\hline aggregate 3 & natural quartz gravel 8/16 & 538 \\
\hline superplasticizer & SIKA Viscocete 5 Neu & 1 \\
\hline
\end{tabular}

Tab. 2. Composition of Mixture B

\begin{tabular}{ccc}
\hline Mixture B & C45/55 & $\mathrm{kg} / \mathrm{m}^{3}$ \\
\hline cement & CEM I 42.5 N & 350 \\
\hline water & & 151 \\
\hline aggregate 1 & natural quartz sand 0/4 & 912 \\
\hline aggregate 2 & natural quartz gravel 4/8 & 485 \\
\hline aggregate 3 & natural quartz gravel 8/16 & 544 \\
\hline superplasticizer & SIKA Viscocete 5 Neu & 1,4 \\
\hline
\end{tabular}

The first LWAC mixture (Mixture C, Tab. 3) has same compressive strength as Mixture A but lower density (the gravel fraction was changed). The compressive strength class is LC25/28 and the density class is D $2.0\left(\rho=1900 \mathrm{~kg} / \mathrm{m}^{3}\right)$. The applied lightweight aggregate was the most popular pellet, expanded clay. The sand fraction was natural quartz sand as usual in load bearing construction.

The next step (Mixture D) was the reduction of compressive strength of LWAC by the reduction of the grade of the cement (CEM III/A $32.5 \mathrm{~N}$ instead of CEM I $42.5 \mathrm{~N}$ ). The new compressive strength class turned to LC20/22 but the density class was unchanged (D 2.0).

The difference between Mixture C and Mixture E is in the type of the lightweight aggregate: expanded clay pellets with lower crushing resistance and lower particle density were used (Liapor HD 5N 4/16 instead of Liapor HD 7N 4/16). Also, the strength and the density of concrete were decreased by one class: LC20/22 and D $1.8\left(\rho=1750 \mathrm{~kg} / \mathrm{m}^{3}\right)$ Tab. 4. The inside structure was the same in all cases over-saturated. The aim of the tests were to study the change of the pullout force when the compressive strength of lightweight aggregate concrete change due to different reasons.

Tab. 3. Composition of Mixture C

\begin{tabular}{ccc}
\hline Mixture C & LC25/28 D 2.0 & $\mathrm{kg} / \mathrm{m}^{3}$ \\
\hline cement & CEM I 42.5 N & 360 \\
\hline water & & 155 \\
\hline aggregate 1 & expanded clay (Liapor HD 7N) 4/16 & 367 \\
\hline aggregate 2 & natural quartz sand 0/4 & 990 \\
\hline superplasticizer & SIKA Viscocete 5 Neu & 3 \\
\hline
\end{tabular}

\subsection{Pull-out test}

The specimens of the pullout tests were blocks of $300 \times 300 \times 100 \mathrm{~mm}$ in size (75 specimens). Specimens were one day in formwork. Then they were stored under water until the $7^{\text {th }}$ day and later in the laboratory at ambient temperature of $20 \pm 2{ }^{\circ} \mathrm{C}$ until the $28^{t h}$ day. The anchors were installed in the middle of the concrete blocks on the $28^{\text {th }}$ day at room temperature and tested after heating and cooled down on the next day 
Tab. 4. Comparison of mixtures

\begin{tabular}{ccccc}
\hline Mixture & Strength class & Density $\left[\mathrm{kg} / \mathrm{m}^{3}\right]$ & Cement type & Aggregate (4/16) type \\
\hline A & C25/30 & 2300 & CEM I 42.5 N & natural quartz gravel \\
\hline B & C45/55 & 2450 & CEM I 42.5 N & natural quartz gravel \\
\hline C & LC25/28 & 1900 & CEM I 42.5 N & Liapor HD 7N \\
\hline D & LC20/22 & 1900 & CEM III 32.5 N & Liapor HD 7N \\
\hline E & LC20/22 & 1750 & CEM I 42.5 N & Liapor HD 5N \\
\hline
\end{tabular}

(Fig. 6). In all mixtures expansion and hybrid bonded anchors were installed, and in two mixtures vinyl ester bonded anchors.

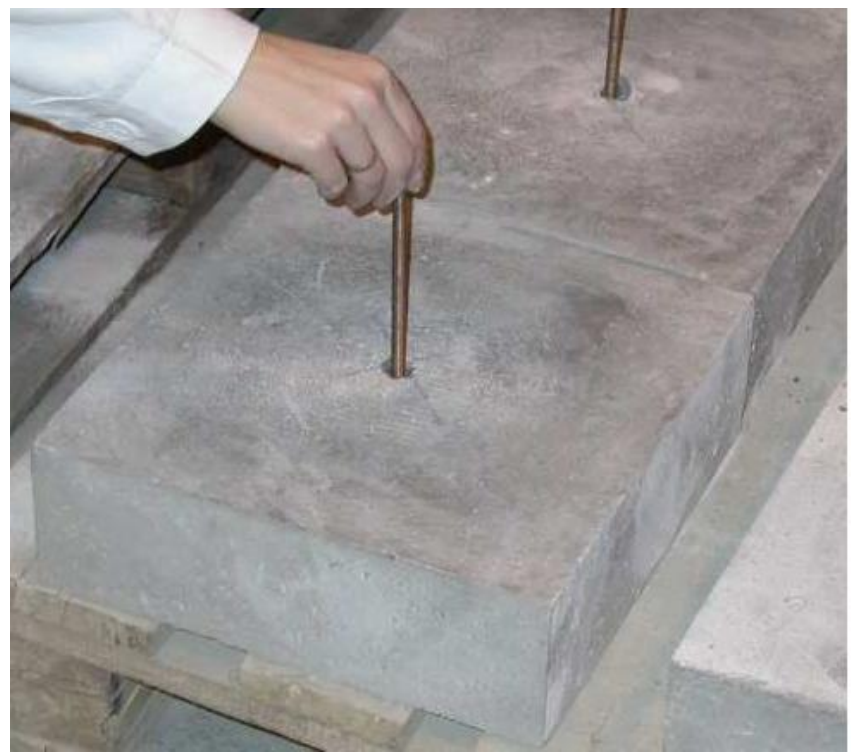

Fig. 6. Installation of the anchors

Parallely sets of standard cubes with edge of $150 \mathrm{~mm}$ were prepared for compressive strength class control. All tests were carried out in the laboratory at the temperature $20 \pm 2^{\circ} \mathrm{C}$ using a force-controlled machine and the relative displacement and the force were continuously recorded (Fig. 7). In our study on expansion and two types of bonded anchors with adhesives of vinyl ester or hybrid (vinyl ester with cement mortar) were tested in five different concrete mixtures and three different temperatures. Test variables are summarised in Tab. 5.

\section{Test results}

\subsection{Influence of aggregate}

\subsubsection{Expansion anchor}

In case of Mixture A (normal weight concrete, C25/30) we have observed at room temperature $\left(20^{\circ} \mathrm{C}\right)$ three different failure modes (three specimens, three failure modes): concrete breakout, tensile strength failure of the bolt or expansion sleeve failure. The failure forces for the different failure modes were nearly the same, because the load-bearing capacity of the anchor and concrete were the same. The average failure force was $21 \mathrm{kN}$. Increasing the strength of concrete $(\mathrm{C} 45 / 55)$, the failure of the bolt was the typical failure mode but the failure force did not increase.
In case of lightweight aggregate concrete of the same strength class (LC25/28) (Mixture C) we observed the failure of the expansion sleeve always. The connection between concrete and anchor decreased, the average of the failure force was $11 \mathrm{kN}$. The failure force was only $50 \%$ from the failure force in case of normal weight concrete (Fig. 8).

If the strength of concrete was decreased by changing the cement grade (Mixture D) the compressive strength of lightweight aggregate concrete decreases too (LC20/22), but the density is unchanged. The failure mode (expansion sleeve breaking) is the same and the average pullout force is similar $(12 \mathrm{kN})$.

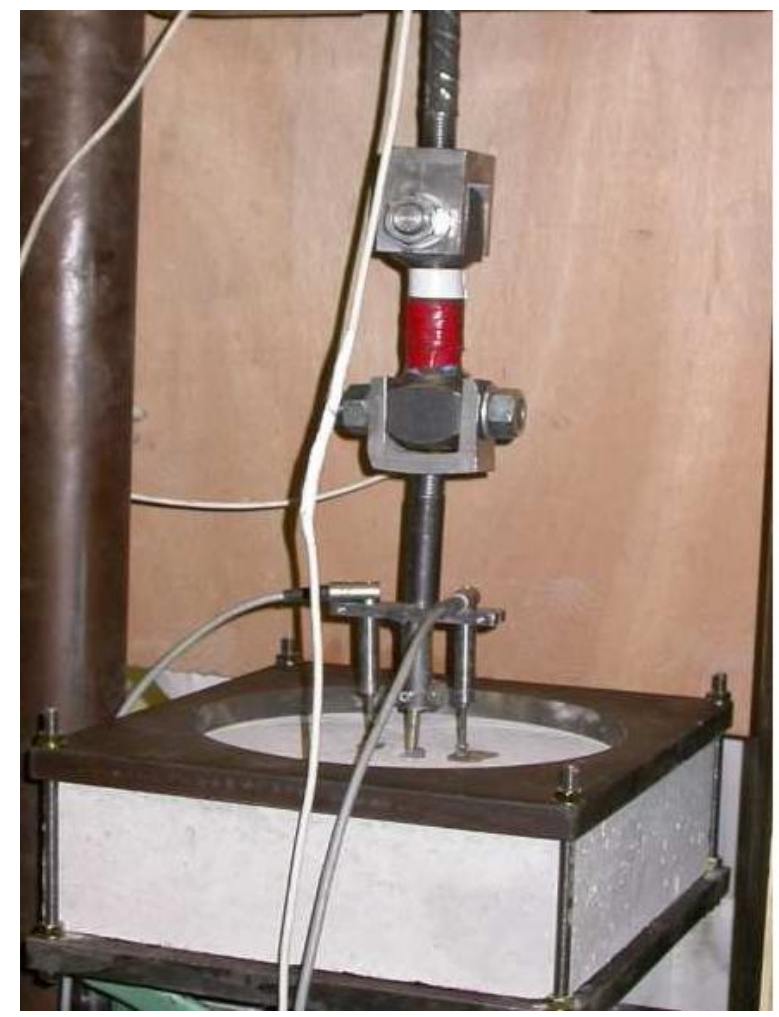

Fig. 7. Pull-out test

If the strength of lightweight aggregate concrete was decreased by changing the crushing resistance of lightweight aggregate, then both the strength class and the density class decreased (Mixture E). The pullout force decreases more $(8 \mathrm{kN})$ by the same failure mode. Accordingly, the decreasing of density has higher influence on failure load bearing capacity than strength. So we can realise that the aggregate has the highest effect on the connection between anchor and concrete. It could 
Tab. 5. The tested anchor types in different concrete mixtures (3 specimens were tested in all cases)

\begin{tabular}{|c|c|c|c|}
\hline & Expansion & $\begin{array}{c}\text { Bonded (hybrid) } \\
\text { (hybrid) }\end{array}$ & $\begin{array}{c}\text { Bonded (vinyl ester) } \\
\text { (vinyl ester) }\end{array}$ \\
\hline Mixture A (C25/30) & $\begin{array}{c}20^{\circ} \mathrm{C} \\
150^{\circ} \mathrm{C}, \\
300^{\circ} \mathrm{C}\end{array}$ & $\begin{array}{c}20^{\circ} \mathrm{C}, \\
150^{\circ} \mathrm{C}, \\
300^{\circ} \mathrm{C}\end{array}$ & $\begin{array}{l}20^{\circ} \mathrm{C}, \\
150^{\circ} \mathrm{C}, \\
300^{\circ} \mathrm{C}\end{array}$ \\
\hline Mixture B (C45/55) & $\begin{array}{l}20^{\circ} \mathrm{C} \\
150^{\circ} \mathrm{C} \\
300^{\circ} \mathrm{C}\end{array}$ & $\begin{array}{c}20^{\circ} \mathrm{C}, \\
150^{\circ} \mathrm{C}, \\
300^{\circ} \mathrm{C}\end{array}$ & $\begin{array}{l}20^{\circ} \mathrm{C}, \\
150^{\circ} \mathrm{C}, \\
300^{\circ} \mathrm{C}\end{array}$ \\
\hline Mixture C (LC25/28 D2.0) & $20^{\circ} \mathrm{C}$ & $20^{\circ} \mathrm{C}$ & - \\
\hline Mixture D (LC20/22 D2.0) & $20^{\circ} \mathrm{C}$ & $20^{\circ} \mathrm{C}$ & $20^{\circ} \mathrm{C}$ \\
\hline Mixture E (LC20/22 D1.8) & $20^{\circ} \mathrm{C}$ & $20^{\circ} \mathrm{C}$ & - \\
\hline
\end{tabular}

be interesting to study lightweight aggregate concrete with the same strength, but with different lightweight pellets. And it would be important to define new catalogue values for calculations for LWAC.

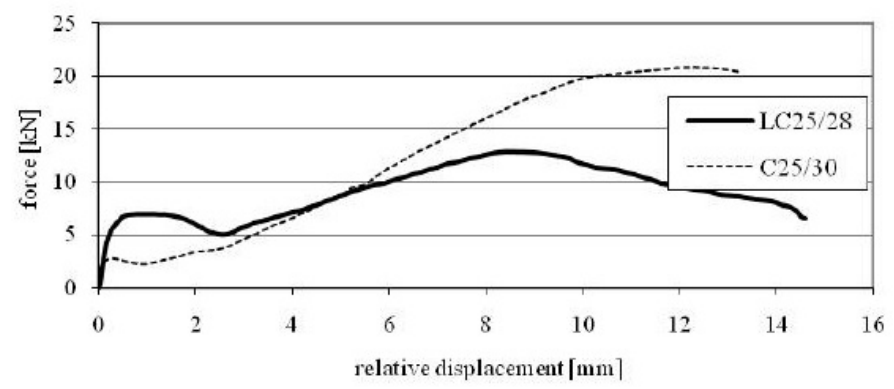

Fig. 8. Force-displacement curves in case of expansion anchor in NWC (Mixture A) and LWAC (Mixture C) block (The curves are the result from the result from one specimen)

\subsubsection{Bonded anchors}

Hybrid bonded anchors In case of normal weight concrete the average pullout force was $20.5 \mathrm{kN}$. The failure mode was the tensile strength failure of the bolt. If we study lightweight aggregate concrete, the force decreases by $20 \%(1516 \mathrm{kN})$ but the maximum forces and the failure modes are always equal (Fig.9) in all LWAC cases: partly pullout and partly break out of a small concrete cone while in most cases the concrete was splitted in two in case the same bolts (Fig. 10).

Vinyl ester bonded anchors In case fo vinyl ester bonded anchors the failure force by normal weight concrete was a little higher than the hybrid bonded $(22.5 \mathrm{kN})$ and the failure mode was the same (tensile strength failure of the bolt). Lightweight aggregate concrete was tested only with Mixture D. The failure force decreased by $30 \%(16 \mathrm{kN})$. The failure mode was the same as in case of the hybrid bonded anchors in LWAC (partly pullout and partly break out of a small concrete cone). All tested types of bonded anchors had higher load bearing capacity than expansion anchor in LWAC (Fig. 11).

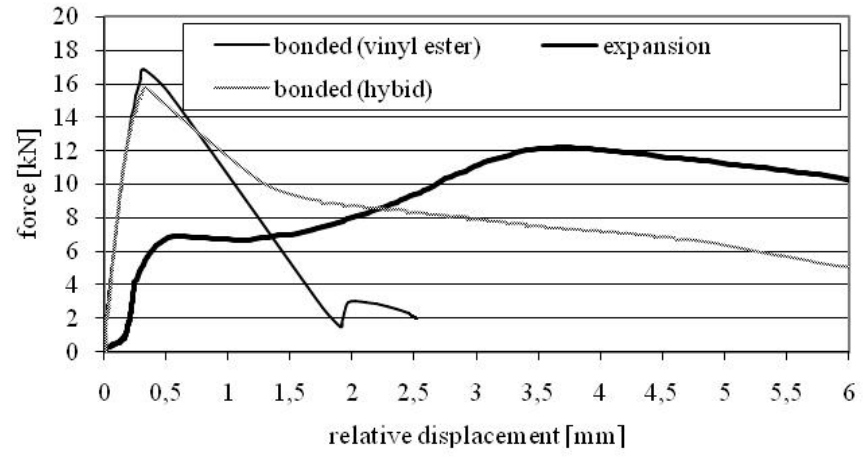

Fig. 9. Force-displacement curves for different LWACs in case of hybrid bonded anchor

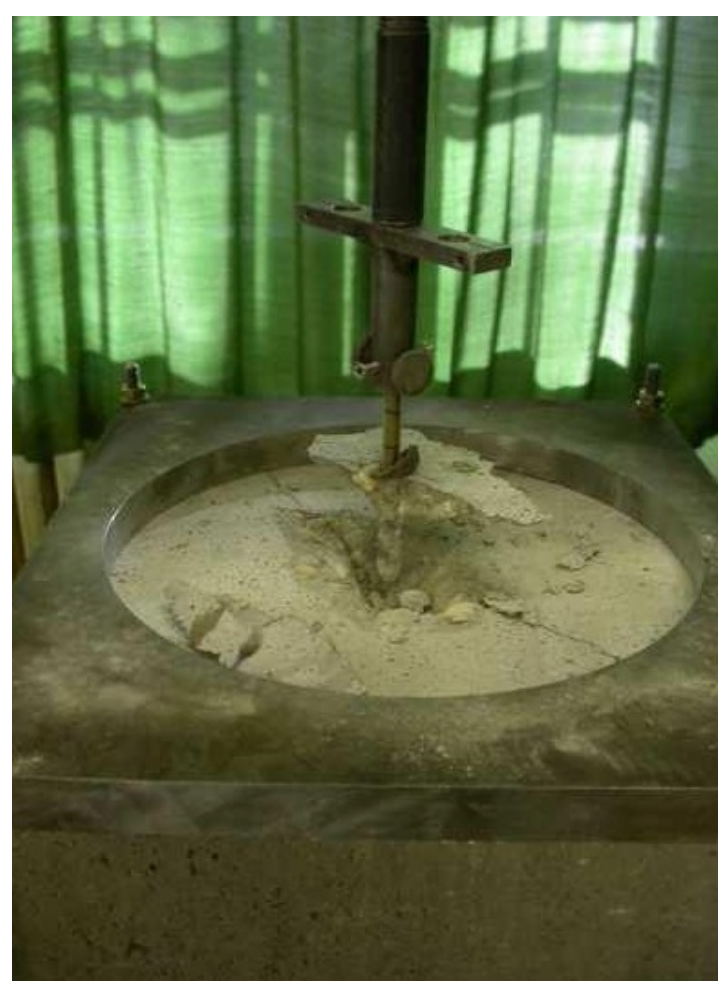

Fig. 10. Typical failure mode of bonded anchor in LWAC 


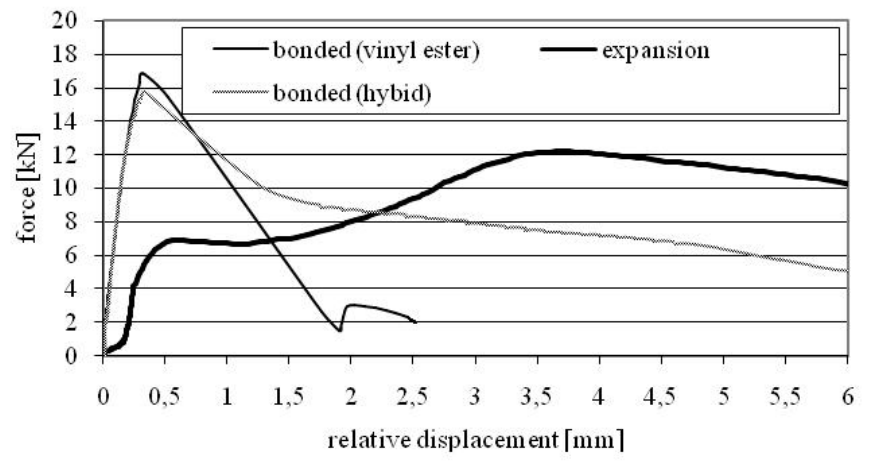

Fig. 11. Force-displacement curves for different types of anchors in case of Mix D

\subsection{Influence of temperature}

\subsubsection{Expansion anchors}

In Fig. 12 we have illustrated the maximum measured force as a function of the temperature in case of torque controlled expansion anchors (FBN 50+63).

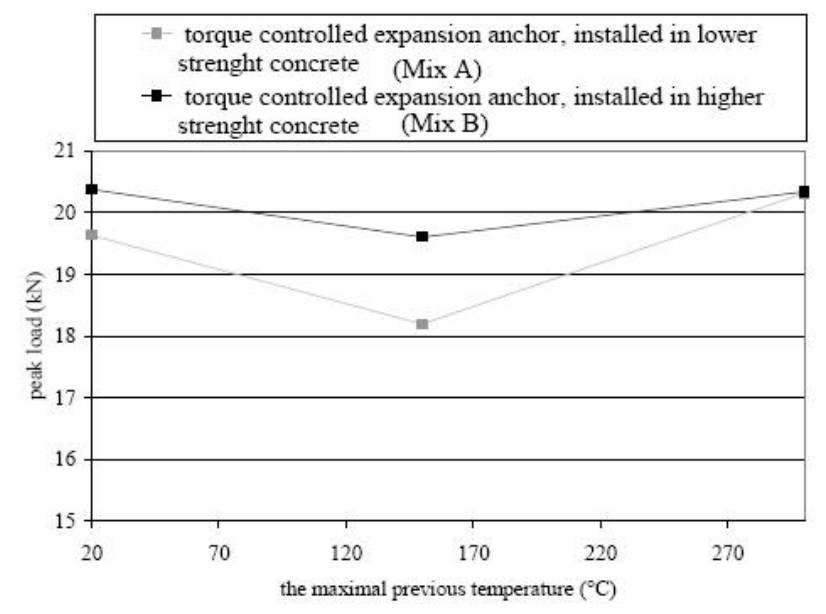

Fig. 12. Peak loads of the torque controlled expanded anchors in function of temperature

In case of expansion anchors we have observed three different failure modes (Fig.12). At room temperature we have observed concrete cone failure. At $150^{\circ} \mathrm{C}$ the anchor head lost its ring and we observed pull-out with concrete splitting (small concrete cone). At $300^{\circ} \mathrm{C}$ we observed steel failure at the minimum diameter of the head. This kind of failure did not cause concrete cone failure. The failure mode depended on the concrete strengths and on the temperature. We have observed steel failure of the anchors in case Mix B at $20^{\circ} \mathrm{C}$ and also after previous temperature loading with $300^{\circ} \mathrm{C}$. In case of Mix A we have observed steel failure of the anchor only after previous temperature loading with $300^{\circ} \mathrm{C}$.

\subsubsection{Bonded anchors}

Peak loads of bonded anchors (FIS A 8-175, anchor, FIS V 360 S, vinyl ester mixed with cement, FIS VT 380 C, vinyl ester) as a function of previous temperature loading were demon-

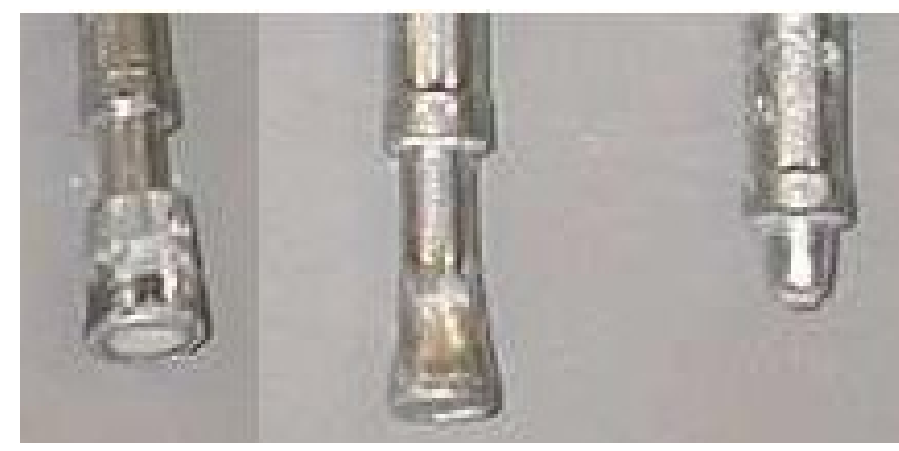

Fig. 13. Failure mode by torque controlled expansions anchors

strated in Fig. 14

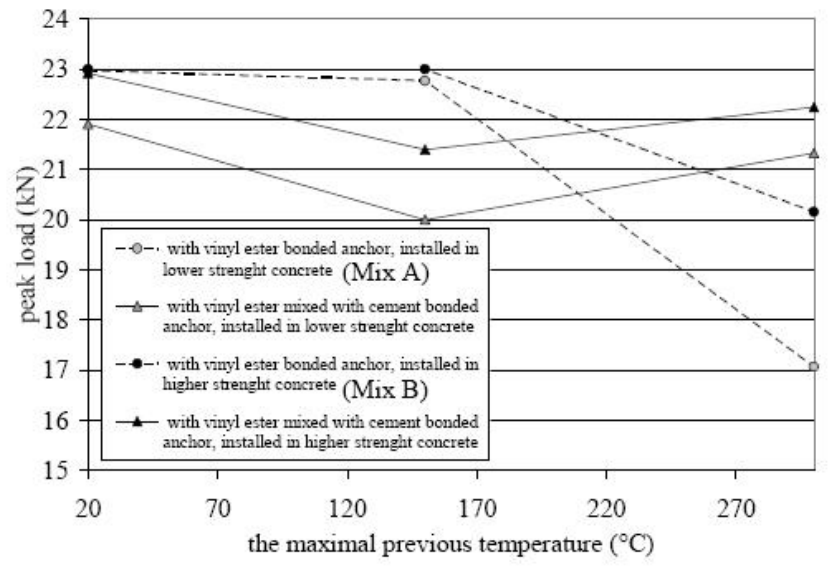

Fig. 14. Peak loads of the bonded anchors in function of temperature

By comparing the continuous lines in Fig. 12 and 14 , we can observe similar tendencies of peak load vs. maximal temperature of previous temperature loading up to $300^{\circ} \mathrm{C}$, for torque controlled expansion anchors or bonded anchors using vinyl ester adhesive mixed with cement. However, these bonded anchors provided slightly higher peak loads.

The failure mode depended also on the concrete strengths and or on the maximal previously temperature [18]. In case of Mix $\mathrm{B}$ we observed concrete cone failure at room temperature after previous temperature loading with $150^{\circ} \mathrm{C}$ and $300^{\circ} \mathrm{C}$. In case of Mix A we observed shallow concrete cone with bond failure at all test temperatures.

Vinyl ester adhesive is more sensitive to the increase of the temperature. We observed steel failure at $20^{\circ} \mathrm{C}$ independent from the bond strength. After previous heating up to $150^{\circ} \mathrm{C}$ we observed different failure modes. In case of higher concrete strength the failure mode was steel failure. In all other cases concrete cone with bond failure was observed. After previous heating up to $300^{\circ} \mathrm{C}$ were in all cases concrete cone with bond failure and significant decrease of bond strength observed.

After the pull out test we analyzed the failed bond surface. We did not observe damage of the adhesive after the previous temperature loading up to $150^{\circ} \mathrm{C}$. After heating up to $300^{\circ} \mathrm{C}$ then cooling it down the adhesive was significantly damaged (Fig. 15. 


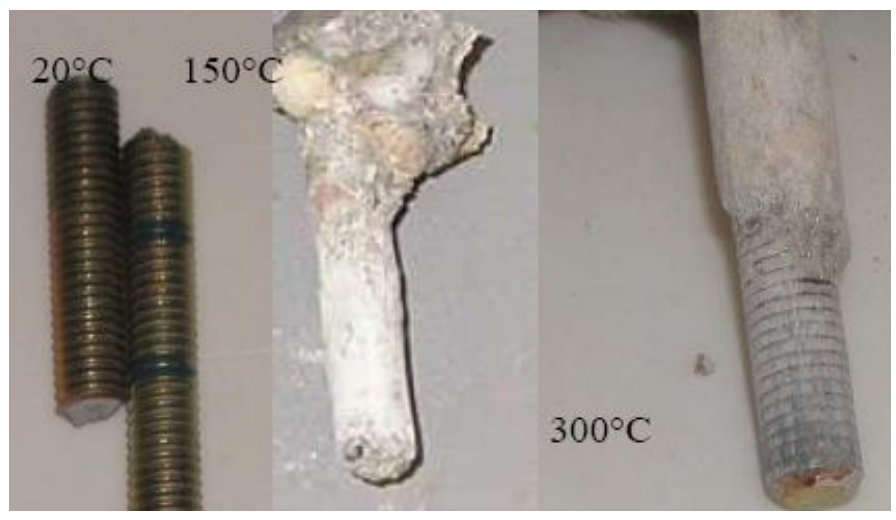

Fig. 15. Failure mode by bonded anchors with vinyl ester

\section{Conclusions}

In our experimental study one type of expansion and two types of bonded anchors (with adhesives of vinyl ester or vinyl ester with cement) were tested in five different concrete mixes. The anchors were installed in concrete blocks.

Application of lightweight aggregate concrete decreases the connection force between anchor and concrete compared to normal weight concrete. The catalogue of anchors specifies only the minimal compressive strength of concrete. In case of the same compressive strength, however, we have measured with lightweight aggregate concrete lower failure force. The biggest reduction appeared in case of the torque-controlled expansion anchors $(50 \%)$ but it was significant in case of bonded anchors (25-30\%), too. The lower the concrete density the lower the pullout load bearing capacity at equal concrete strength class.

The failure mode depends in all cases on concrete strengths and the maximal previous temperature. Torque controlled expansion anchors or bonded anchors using vinyl ester adhesive mixed with cement have similar tendencies of peak loads vs. maximal temperature of previous temperature loading up to $300^{\circ} \mathrm{C}$. Vinyl ester adhesive is more sensitive to the increase of the temperature. The peak loads after the previous temperature loading up to $300^{\circ} \mathrm{C}$ were significantly reduced by bonded anchors using vinyl ester adhesive.

\section{References}

1 Eligehausen R, Fuchs W, Sippel T, Anchorage to Concrete, TARTOK 2000 (Budapest, 2000), 2000, pp. 261-270.

2 CEB, CEB Bulletin No. 206, Fastenings to Reinforced Concrete and Masonry Structures, CEB, Vienne, 1991.

3 Simons I, Eligehausen R, Kirtzakis V, Behaviour of Post-Installed Rebars in Uncracked and Cracked Concrete, Keep Concrete Attractive (Budapest, 2005), 2005, pp. 669-674.

4 Szabó K Zs, Balázs L Gy, Near surface mounted FRP reinforcement for strengthening of concrete structures, Periodica Politechnica, Civil Engineering 51 (2007), no. 1, 33-38, DOI 10.1016/S0263-8231(02)00025-3.

5 Spieth $\mathbf{H}$, Eligehausen R, Design of post-installed rebar connections, Bond in Concrete - from research to standards (Budapest, 2002), 2002, pp. 439-446.

6 Nemes R, Józsa Zs, Strength of Lightweight Glass Aggregate Concrete, ASCE Journal of Materials in Civil Engineering 18 (2006), no. 5, 710-714.
7 EN, ENÂ 206-1:2000 Concrete - Part 1: Specification, performance, production and conformity, EU, Brussel, 2000.

8 Fehérvári S, Salem G N, Near surface mounted FRP reinforcement for strengthening of concrete structures, Periodica Politechnica, Civil Engineering 53 (2009), no. 1, 15-23, DOI 10.3311/pp.ci.2009-1.03.

9 fib, fib Bulletin 8 Lightweight Aggregate Concrete, Recommended extensions to Model Code 90; Case studies, Sprint-Druck, Stuttgart, 2000.

10 Hittenberger R, Brandschutz von Befestigungsdetails und das Temperaturverhalten der Verbundanker in Beton (Fire protection of fastening assemblies and the behaviour under fire exposure of bonded anchors), University of Innsbruck, Innsbruck, 1998.

11 Bamonte P, Gambarova P G, Residual behavior of undercut fasteners subjected to high temperatures, Keep Concrete Attractive (Budapest, 2005), 2005, pp. 1156-1163.

12 _ Residual Capacity of Undercut Fasteners Installed in Thermallydamaged Concrete, 2nd fib International Congress (2006), 2006, pp. 32-42.

13 Sell R, Tragfähigkeit von mit Reaktionharzmörterpatronen versetzten Betonankern und deren Berechnung (Load capacity of anchors fixed in concrete with resin mortar cartridges), Die Bautechnik, 1973.

14 Rehm G, Eligehausen R, Mallée R, Befestigungstechik, Betonkalender, Berlin, 1998.

15 Wiewel H, Temperature Sensitivity Tests on High Strength Bonded Anchors, Tec mar, Inc. Long Beach, CA, 1991.

16 Ožbolt J, Kožar I, Eligehausen R, Periskic G, Thermal 3D FE Analysis of Headed Stud Anchors Exposed to Fire, Proceedings for Fire Design of Concrete Structures: What now?, What next? (2004), 2004, pp. 32-42.

17 Fischer Anchors Catalogue, 2005.

18 Majoros É, Balázs Gy L, Degree of deterioration due to fire in large concrete halls, Periodica Politechnica, Civil Engineering 48 (2003), no. 1, 141156. 